\title{
Promotion Countermeasures of the Core Competence of Modern Service Industry in the New Normal-Taking Hefei as an Example
}

\author{
Wang Junfeng ${ }^{1}$, Li Yuhua ${ }^{1 *}$ \\ ${ }^{1}$ Institute of Management Modernization, The School of Management, Hefei University of \\ Technology, Anhui, China, 230009 \\ *Corresponding Author: Li Yuhua
}

Keywords: Industrial Structure, Factor Analysis Method, Modern Service Industry, Evaluation Model of Core Competence

\begin{abstract}
The upgrading of the industrial structure adjustment accelerates the pace and the content of modern service industry is changing constantly. Due to the importance of modern service industry in the transition of economic development in the new normal, it is particularly important to further promote the sustainable development of modern service industry and enhance the core competitiveness in the 13th Five-year plan. According to the principle of qualitative and quantitative analysis, this paper makes use of the principal component analysis to select the appropriate evaluation indexes to reestablishthe scientific and reasonable index system. Drawing on the construction of core competence evaluation model of other industries, this paper uses factor analysis method to establish a new evaluation model of core competence of modern service industry to explore the internal law of the development of modern service industry. Finally, the validity and applicability of the evaluation indicators and evaluation model are verified by the statistical data of modern service industry in Hefei. Satisfied results are achieved by comparing with other provincial capitals and municipalities.
\end{abstract}

\section{Evaluation Results Analysis}

After calculation, we obtain the score and sort of the core competence of modern service industry in 31 provincial capitals and municipalities in the new normal in China. As the Table 1 shows:

Table 1 The score and sort of the core competence of modern service industry in 31 provincial capitals and municipalities in China

\begin{tabular}{|c|c|c|c|c|c|c|c|c|}
\hline \multirow{2}{*}{ Region } & \multicolumn{2}{|c|}{ General Consideration } & \multicolumn{2}{|c|}{ First Main Factor } & \multicolumn{2}{|c|}{ Second Main Factor } & \multicolumn{2}{|c|}{ Third Main Factor } \\
\hline & $\mathrm{F}$ & rank & $\mathrm{F} 1$ & rank & F2 & rank & F3 & rank \\
\hline Shanghai & 1.822449 & 1 & 2.9262 & 1 & 3.40749 & 1 & 1.24486 & 2 \\
\hline Beijing & 1.48604 & 2 & 2.30887 & 2 & 1.40172 & 3 & 3.3333 & 1 \\
\hline Guangzhou & 1.04576 & 3 & 0.83256 & 5 & 1.39191 & 4 & 1.03879 & 4 \\
\hline Tianjin & 0.944188 & 4 & 1.87972 & 3 & 2.88529 & 2 & 0.95145 & 5 \\
\hline Nanjing & 0.932937 & 5 & 0.90359 & 4 & 0.26718 & 6 & 0.7356 & 6 \\
\hline Hangzhou & 0.849975 & 6 & 0.5498 & 7 & 0.21307 & 7 & 1.08842 & 3 \\
\hline
\end{tabular}




\begin{tabular}{|l|c|c|c|c|c|c|c|c|} 
Chongqing & 0.378601 & 7 & 0.72849 & 6 & 0.11666 & 8 & 0.72603 & 7 \\
\hline Chengdu & 0.195831 & 8 & 0.5499 & 8 & 0.52148 & 5 & 0.62274 & 9 \\
\hline Wuhan & 0.152793 & 9 & 0.29162 & 9 & -0.03687 & 10 & 0.6856 & 8 \\
\hline Shenyang & 0.128216 & 10 & -0.10782 & 12 & 0.07377 & 9 & 0.01122 & 14 \\
\hline Jinan & 0.079613 & 11 & -0.24542 & 16 & -0.33587 & 16 & 0.2459 & 11 \\
\hline Xi'an & 0.052101 & 12 & -0.17519 & 13 & -0.08298 & 11 & 0.39455 & 10 \\
\hline Zhengzhou & -0.01604 & 13 & -0.26459 & 17 & -0.44644 & 18 & 0.05229 & 13 \\
\hline Changsha & -0.0843 & 14 & 0.28899 & 10 & -0.49843 & 20 & -0.00691 & 15 \\
\hline Hefei & -0.12149 & 15 & -0.19056 & 14 & -0.30046 & 14 & -0.10932 & 17 \\
\hline Harbin & -0.27392 & 16 & 0.24663 & 11 & -0.13696 & 12 & -0.10786 & 16 \\
\hline Fuzhou & -0.27608 & 17 & -0.27853 & 18 & -0.27697 & 13 & -0.37396 & 19 \\
\hline Changchun & -0.28935 & 18 & -0.20631 & 15 & -0.37174 & 17 & -0.54713 & 21 \\
\hline Shijiazhuang & -0.29083 & 19 & -0.48132 & 23 & -0.56708 & 22 & -0.61888 & 24 \\
\hline Nanchang & -0.31639 & 20 & -0.35877 & 19 & -0.57674 & 23 & 0.15592 & 12 \\
\hline Taiyuan & -0.32507 & 21 & -0.37279 & 20 & -0.49635 & 19 & -0.316 & 18 \\
\hline Nanning & -0.37303 & 22 & -0.38807 & 21 & -0.54225 & 21 & -0.48803 & 20 \\
\hline Kunming & -0.38805 & 23 & -0.47733 & 22 & -0.33064 & 15 & -0.57677 & 23 \\
\hline Lanzhou & -0.4581 & 24 & 0.55984 & 28 & -0.58517 & 24 & -0.54858 & 22 \\
\hline Guiyang & -0.53889 & 25 & -0.69323 & 26 & -0.60605 & 25 & -0.64569 & 25 \\
\hline Haikou & -0.61362 & 26 & -0.69126 & 25 & -0.60676 & 26 & -0.78681 & 28 \\
\hline Hohhot & -0.67233 & 27 & -0.93678 & 27 & -0.61806 & 27 & -0.67222 & 26 \\
\hline Urumqi & -0.68083 & 28 & -0.67785 & 24 & -0.66952 & 29 & -0.76478 & 27 \\
\hline Xining & -0.72655 & 29 & -1.2362 & 29 & -0.90335 & 31 & -1.21322 & 29 \\
\hline Yinchuan & -0.7816 & 30 & -1.24561 & 30 & -0.67124 & 30 & -2.24369 & 31 \\
\hline Lhasa & -0.84199 & 31 & -1.31018 & 31 & -0.61863 & 28 & -1.26681 & 30 \\
\hline
\end{tabular}

From Table 1, we can see that the core competence of modern service industry of Hefei is ranked 15 th in national regions in the new normal. The features of the core competence of modern service industry are:

In the evaluation of the core competence of modern service industry, China's easterncoastal areas have good advantages. The central areas of China are the middle of the list. The western China's core competence of modern service industry is weakest. However, Chengdu and Chongqing are at top 10. Seven cities of the top ten are eastern China's cities. Therefore, the core competence of modern service industry of eastern China is in the absolutely leading position. The highest score of eastern China is 12 times higher than the highest score of western China. It is also ten times higher than that of central China.

The core competence of modern service industry of Hefei is ranked 4th among six provinces in central China, which is behind the cities of Wuhan, Changsha and Zhengzhou and front of Nanchang and Taiyuan. It is at the intermediate level in the six provincial capitals.

From the point of view of all factor scores, Hefei ranks 14th in the capital factor (F1) ranked 14, ranks 14th in the scientific research strength factor (F2) and ranks 17th in the professional level factor (F3). These indicators show that: in recent years, compared with other provincialcapital cities and municipalities directly under the central government, with Hefei undertaking industrial transfer and the construction of the strategy implementation of Wanjiang City Belt, the advantages of the level of consumption, real estate and other indicators are embodies through the capital factor (F1). 
Under the new normal, the core competitiveness of modern service industry in Hefei in terms of financial resources, there is a great space for development. As the demonstration city of science and education innovation, scientific research strength, technical level, the training of scientific and technological personnel is at the higher level. The scientific research strength factor (F2) proves this point. In addition, from Hefei city core competitiveness of modern service industry professional level factor ranking, we can also see that modern service industry specific professional development level is still at the relatively low level in the new normal in Hefei, leading to lack of stamina to enhance the core competitiveness. The modern service industry industrial structure adjustment efficiency is lowand the upgrading is not obvious in Hefei.

We use the same method to divide all the indexes into the competitiveness index elements below the competitiveness of system and the competitiveness of ecology. Then, we calculate the evaluation model respectively, verifying the results of core competence. The formulation of core competenceof modern service industry system in Hefei is as follows:

$$
F=\left(0.4637 * F_{1}+0.3913 * F_{2}\right) / 77.727
$$

F1 is a knowledge aggregation factor, which has strong loading and explanatory abilityof the factor, such as scientific research and science and technology service industry increase in value, finance and insurance industry added value, the specialized service industry added value, information value added services. F2 is a flow factor which has strong loading and interpretation ability of modern logistics industry increase in value and convention and exhibition tourism industry added value. In addition, we can get the modern service industry system competitiveness of Hefei ranks 15th in the new normal.

The evaluation model of core competitiveness of ecology of modern service industry in Hefei is as follows:

$$
F=\left(0.58893 * F_{1}+0.31023 * F_{2}\right) / 89.916
$$

Among the above formulation, F1 is the factor of economicsource, which has strong loading and explanatory ability of the factors of passenger volume, GDP of the city, urban residents' per capita disposable income, price index and the level of savings deposits of urban and rural residents. F2 is scientific research strength factor, which has good loading and interpretation ability of the factors of the ordinary higher school in the total number of school and the patent authorization quantity factor. In addition, we can get that the core competence of ecology of modern service industry in Hefei ranks 14th in the national regions in the new normal.

The evaluation of the core competence is verified by the evaluation of the two competitiveness models, and the results are generally consistent. The total capital economic scale is relatively large and the scientific research strength is also very strong, which can contribute to the improvement of the core competence in a big degree. The development of some specific professional fields is not so good. The possible reasons may be deficient innovations andinadequate talents. These reasons will lead to the imperfect internal structure and insufficient integration of modern service industry in the new normal, which hinder the transformation, upgrading and the sustainable promotion of core competitiveness.

\section{Acknowledgements}

Fund Project: Subject of 13th Five-Year Planning and Study of Modern Service Industry of State Commission of Development and Reform in Hefei 


\section{References}

[1] Fai'zGallouj.2002.Innovation in the service economy: the new wealthof nations .2002 Edward Elgar Publishing Limited;

[2] Zhang Yi, Zhao Huifang, Wang Chong, Evaluation on Development Level of Modern Service Industry ofAnhui Province Based on Principal Component Analysis, Journal of Hefei University of Technology (Social Sciences), 2008, 22(4): 48-52. 